NASA

Technical

Paper

2868

1989

\title{
Mixed Finite Element Models for Free Vibrations of Thin-Walled Beams
}

Ahmed K. Noor, Jeanne M. Peters, and Byung.Jin Min The George Washington University Joint Institute for Advancement of Flight Sciences Langley Research Center Hampton, Virginia

National Aeronautics and Space Administration Office of Management Scientific and Technical Information Division 


\section{Contents}

Summary . . . . . . . . . . . . . . . . . . . . . . . 1

Introduction . . . . . . . . . . . . . . . . . . . . . . . 1

Symbols . . . . . . . . . . . . . . . . . . . . . . . . . . 1

Mathematical Formulation . . . . . . . . . . . . . . . . . . . . 2

Comments on Perturbed Lagrangian Formulation _ . . . . . . . . . . . . . . . . . . . . 3

Numerical Studies . . . . . . . . . . . . . . . . . . . . . . . . . . . . . . . . . . . 3

Cantilever Beams With Channel Cross Sections . . . . . . . . . . . . . . . . . . . . 4

Semicircular Beams With Z-Sections . . . . . . . . . . . . . . . . . . . . . . 4

Concluding Remarks . . . . . . . . . . . . . . . . . . . . . . . 5

Acknowledgment . . . . . . . . . . . . . . . . . . . . . . . 5

Appendix A-Fundamental Equations of Thin-Walled Beam Theory Used in Present Study . . . 6

Displacement Assumptions . . . . . . . . . . . . . . . . . . . . . . . 6

Strain Assumptions . . . . . . . . . . . . . . . . . . . . . . . . . . . . . . . . 6

Constitutive Relations . . . . . . . . . . . . . . . . . . . . . . . . . . 7

Variational Functional . . . . . . . . . . . . . . . . . . . . . . 7

Appendix B-Formulas for Coefficients in Governing Equations for Individual Elements . . . . . 9

References .............................. 10

Tables ........................... 11

Figures ............................. 12 


\section{Summary}

Simple, mixed finite element models are developed for the free-vibration analysis of curved, thinwalled beams with arbitrary open cross section. The analytical formulation is based on a linear, Vlasovtype, thin-walled beam theory with the effects of flexural-torsional coupling, transverse shear deformation, and rotary inertia included. The fundamental unknowns consist of seven internal forces and seven generalized displacements of the beam. The element characteristic arrays are obtained by using a modified form of the Hellinger-Reissner mixed variational principle. The modification consists of augmenting the functional of that principle by two terms: (1) the Lagrange multiplier associated with the constant condition relating the rotation of the cross section and the twist degrees of freedom, and (2) a regularization term that is quadratic in the Lagrange multiplier. Only $\mathrm{C}^{0}$ continuity is required for the generalized displacements. The internal forces and the Lagrange multiplier are allowed to be discontinuous at interelement boundaries.

Numerical results are presented to demonstrate the high accuracy and effectiveness of the elements developed. The standard of comparison is taken to be the solutions obtained by using two-dimensional plate/shell models for the beams.

\section{Introduction}

Since the development of the comprehensive theory of combined torsion and bending of thin-walled beams by Vlasov in the 1930's (see Vlasov 1961), extensive literature has been devoted to the application and adaptation of the theory to a variety of equilibrium, stability, and vibration problems of thin-walled structures. Reviews of the many contributions on this subject are given in a number of survey papers (see, for example, Nowinski 1966 and Panovko and Beilin 1969) and monographs (Gjelsvik 1981; Kollbrunner and Basler 1969; Vlasov 1961; and Zbirohowski-Kos̀cia 1967). Several finite element models, based on Vlasov's theory, have been proposed in the literature for the equilibrium, stability, and vibration analysis of thin-walled beams. (See Attard 1986; Barsoum and Gallagher 1970; Epstein and Murray 1976; Friberg 1985; Kiss 1986; Krajcinovic 1969; Mei 1970; Rozmarynowski and Szymczak 1984; Tralli 1986; and Wekezer 1987.) Also, a number of commercial programs have thin-walled beam models in their element libraries. (See, for example, Kiss 1986.) However, except for the hybrid model and the modified displacement model described in Kiss (1986) and Tralli (1986), all the other finite element models developed are based on a standard displacement formulation that requires $C^{1}$ continuity for the torsional degrees of freedom. Despite the documented advantages of mixed formulations in finite element modeling, to date no publications exist in which mixed finite elements are used for modeling thin-walled beams. The present study attempts to fill this void. Specifically, the objectives of this paper are: (1) to present simple and efficient mixed finite element models for the free-vibration analysis of curved thin-walled beams with arbitrary open cross section, and (2) to demonstrate the effectiveness of these elements by means of a numerical comparison with results of two-dimensional models.

To sharpen the focus of the study, only prismatic thin-walled beams with open cross section are considered. The wall thickness is assumed to be constant, and the material is linearly elastic and isotropic. The analysis can be extended to anisotropic beams with variable geometric and material characteristics.

\section{Symbols}

A

$A_{y}, A_{z}$

$B_{\omega}$

$b$

E

$[F]$

$G$

$\{H\}$

$I_{y}, I_{z}, I_{y z}$

$I_{\omega}, I_{\omega y}, I_{\omega z}$

$J$

$K$

$L$

$l$

$[M]$

$M_{y}, M_{z}, M_{t}$

$\mathbf{m}$ cross-sectional area

effective shear areas in $y$ - and $z$-directions, respectively

bimoment

flange (or web) dimension

Young's modulus

linear flexibility matrix for an individual element

shear modulus

vector of internal force parameters

second moments of cross section (moments and product of inertia)

second sectorial moments of cross section

Saint-Venant torsion constant of cross section

kinetic energy

beam length

length of individual finite element

consistent mass matrix for individual element

bending and twisting moments number of displacement nodes in element 


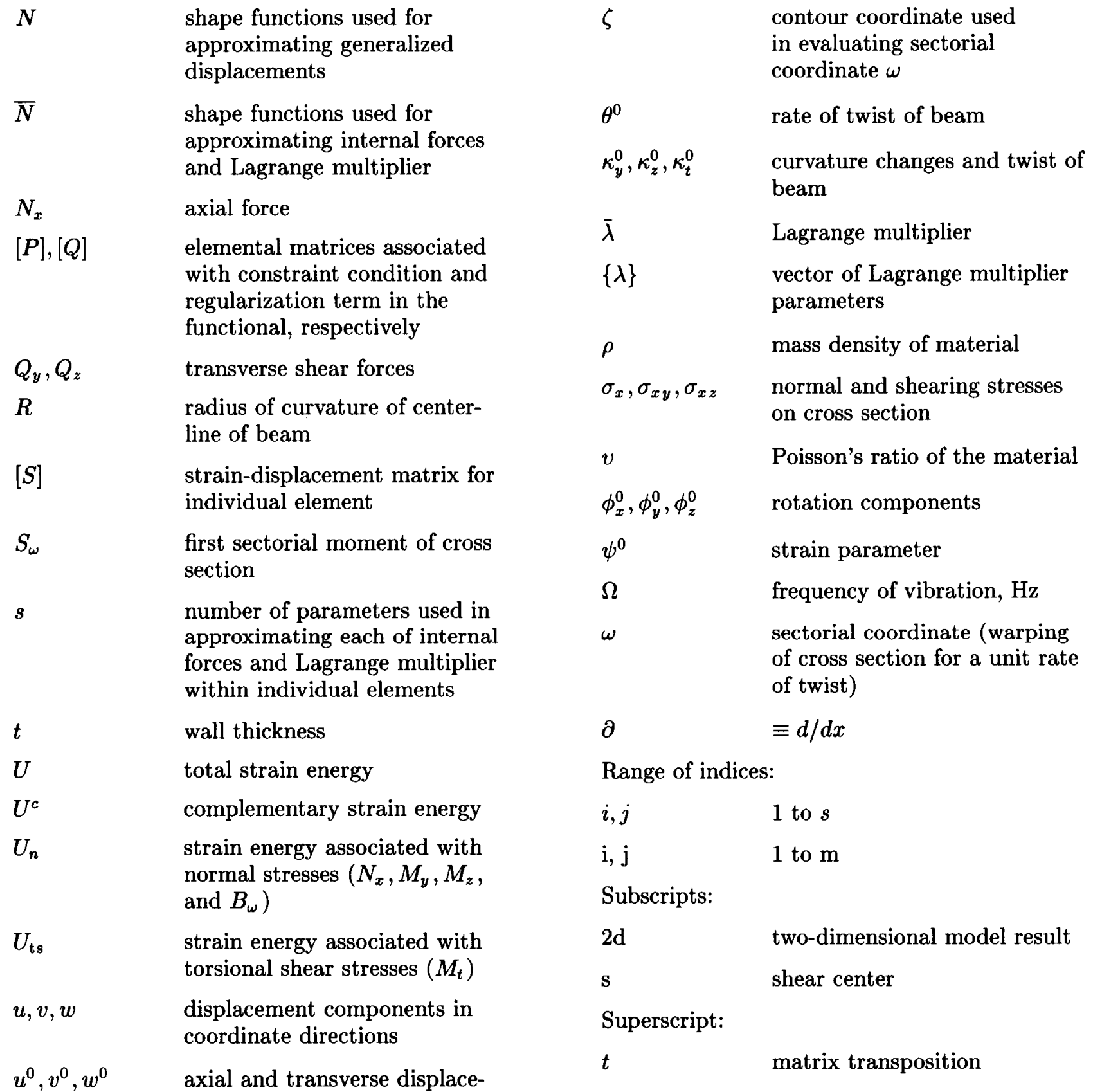

$\{X\} \quad$ vector of nodal displacements

$x, y, z \quad$ orthogonal coordinate system with $x$ passing through centroids of cross sections

$\gamma_{x y}, \gamma_{x z}, \quad$ transverse shear strains (see $\gamma_{x y}^{0}, \gamma_{x z}^{0} \quad$ eqs. (A2), appendix A)

$\varepsilon \quad$ penalty parameter

$\varepsilon_{x} \quad$ extensional strain

$\varepsilon_{x}^{0} \quad$ extensional strain of centerline of beam

\section{Mathematical Formulation}

The analytical formulation is based on a linear form of Vlasov's thin-walled beam theory with the effects of flexural-torsional coupling, transverse shear deformation, and rotary inertia included. A mixed formulation is used in which the fundamental unknowns consist of the seven generalized displacements and seven internal forces. The generalized displacements consist of the axial and transverse displacement components of the centroid $u^{0}, v^{0}$, and $w^{0}$; the three rotation components $\phi_{x}^{0}, \phi_{y}^{0}$, and $\phi_{z}^{0}$; and the rate of twist of the beam $\theta^{0}$. The seven internal forces consist of the axial force $N_{x}$; the two 
transverse shear forces $Q_{y}$ and $Q_{z}$; the two bending moments $M_{y}$ and $M_{z}$; the twisting moment $M_{t}$; and the bimoment $B_{\omega}$. The sign convention for the generalized displacements and internal forces is given in figure 1. The fundamental equations of the thinwalled beam theory used herein are summarized in appendix A. In order to reduce the continuity requirements for all the generalized displacements to $\mathrm{C}^{0}$, a modified form of the Hellinger-Reissner mixed variational principle (Washizu 1974) is used in the development of the element characteristics. The modification amounts to augmenting the functional of that principle by two terms: the Lagrange multiplier associated with the constraint condition relating $\phi_{x}^{0}$ and $\theta^{0}$, and a regularization term that is quadratic in the Lagrange multiplier. (See appendix A.) For a detailed discussion of the augmented (perturbed) Lagrangian formulation, see Fortin and Glowinski (1983).

The shape functions used in approximating the internal forces and the Lagrange multiplier are selected to be the same but are different from those used in approximating the generalized displacements. Moreover, the continuity of both the internal forces and the Lagrange multiplier is not imposed at interelement boundaries.

The finite element equations for each individual element can be cast in the following compact form:

$$
\left[\begin{array}{ccc}
-F & \cdot & S \\
\cdot & \frac{P}{\varepsilon} & Q^{2} \\
S^{t} & Q & \cdot
\end{array}\right]\left\{\begin{array}{c}
H \\
\lambda \\
X
\end{array}\right\}=\Omega^{2}\left[\begin{array}{ccc}
\cdot & \cdot & \cdot \\
\cdot & \cdot & \cdot \\
\cdot & \cdot & M
\end{array}\right]\left\{\begin{array}{c}
H \\
\lambda \\
X
\end{array}\right\}
$$

where $\{H\},\{\lambda\}$, and $\{X\}$ are the internal force parameters, Lagrange multiplier parameters, and nodal displacements, respectively; $[F]$ is the matrix of linear flexibility coefficients; $[S]$ is the strain-displacement matrix; $[P]$ and $[Q]$ are matrices associated with the constraint condition and the regularization term in the functional, respectively (see appendix $\mathrm{A}) ;[M]$ is the consistent mass matrix; $\Omega$ is the frequency of vibration; $\varepsilon$ is a penalty parameter associated with the regularization term; and a dot (.) refers to a zero submatrix. The formulas for the elemental arrays $[F],[S],[P],[Q]$, and $[M]$ are given in appendix $\mathrm{B}$.

If the internal force parameters and the Lagrange multiplier parameters are eliminated from equations (1), one obtains the following equation in the nodal displacements $\{X\}$ :

$$
\left([S]^{t}[F]^{-1}[S]-\varepsilon[Q][P]^{-1}[Q]^{t}\right)\{X\}=\Omega^{2}[M]\{X\}
$$

\section{Comments on Perturbed Lagrangian Formulation}

The following three comments regarding the perturbed Lagrangian formulation used herein seem to be in order:

1. The governing finite element equations of the perturbed Lagrangian formulation (eqs. (1)) include both those of the Lagrange multiplier approach and the penalty method as special cases as follows:

(1) By letting the penalty parameter $\varepsilon$ go to infinity, equations (1) reduce to those of the Lagrange multiplier approach.

(2) By eliminating the Lagrange multiplier terms from equations (1), the resulting equations are identical to those of the penalty method.

2. The perturbed Lagrangian formulation, in addition to reducing the continuity requirements for the generalized displacements in the element development, alleviates two of the drawbacks of the Lagrange multiplier approach and the penalty method, namely:

(1) The regularization term in the functional results in replacing one of the zero diagonal blocks in the discrete equations of the Lagrange multiplier approach by the diagonal matrix $[P] / \varepsilon$ in equations (1).

(2) The constraint condition relating the rotation of the cross section $\phi_{x}^{0}$ and the rate of twist $\theta^{0}$ (see appendix A) is enforced exactly in the functional rather than approximately as in the penalty method. However, the presence of the regularization term results in replacing the constraint condition by the perturbed condition (on the element level):

$$
\frac{[P]}{\varepsilon}\{\lambda\}+[Q]^{t}\{X\}=0
$$

3. An important consideration in the perturbed Lagrangian formulation is the proper selection of the penalty parameter $\varepsilon$. With the foregoing mixed models, the penalty parameter can be chosen independently of the element size without adversely affecting the performance of the model. The accuracy of the solution increases with increasing value of the penalty parameter. However, for very large values of $\varepsilon$, ill-conditioning of the equations occurs, thereby increasing the round-off errors. In the present study, for convenience, the penalty parameter $\varepsilon$ was chosen to be equal to the extensional stiffness of the beam $E A$.

\section{Numerical Studies}

To test and evaluate the performance of the foregoing mixed models, a large number of vibration 
problems of thin-walled beams with open cross section have been solved by using these models. For each problem, comparison was made with solutions obtained by using two-dimensional plate/shell elements in modeling the beam, and also with previously published solutions whenever available. Herein, the results of two sets of free-vibration problems are discussed. The two problems are: (1) a straight cantilever beam with symmetric and unsymmetric channel cross sections; and (2) a semicircular beam with a Z-shaped section (Z-section) and clamped ends. A classical Rayleigh-Ritz solution along with test results for the first problem are given by Gere and Lin (1958). Also, a finite element solution for the same problem based on displacement models is given by Mei (1970).

In each case, the structure was analyzed using (1) the mixed one-dimensional models developed herein, and (2) two-dimensional plate/shell models based on a Sanders-Budiansky type of shell theory with the effects of transverse shear deformation and rotary inertia included. (See Noor and Andersen 1982 and Noor and Peters 1983 for a description of the finite element model used.) In the onedimensional models, Lagrangian interpolation functions were used for approximating each of the generalized displacements, internal forces, and Lagrange multiplier. The polynomial functions for the internal forces and the Lagrange multiplier were one degree lower than those of the generalized displacements. The characteristics of the finite element models in the numerical studies are summarized in table I. In all the solutions presented herein, only the displacement boundary conditions are enforced and the force boundary conditions are not applied. Typical results are presented in figures 2 through 7 for the cantilever beams with channel sections and in figures 8 through 12 for the semicircular beams with Z-sections. Also, table II lists the minimum six frequencies obtained by the thin-walled beam and twodimensional models for the unsymmetric channel section and Z-section.

\section{Cantilever Beams With Channel Cross Sections}

The first problem set considered is that of the cantilever beams with the symmetric and the unsymmetric channel cross sections shown in figure 2 . The vibration mode shapes for the beam with symmetric channel section, obtained by the two-dimensional model, are shown in figure 3 . The ratios of the strain energies associated with normal stresses and torsional shear stresses to the total strain energy, $U_{n} / U$ and $U_{\mathrm{ts}} / U$, for the first six vibration modes are shown in figure 4 . Note that $U_{n}$ is associated with $N_{x}, M_{y}, M_{z}$, and $B_{\omega}$; and $U_{\mathrm{ts}}$ is associated with $M_{t}$. Except for the second and sixth modes of the beam with symmetric channel section, all the other modes exhibit strong flexural-torsional coupling. This strong coupling cannot be predicted by ordinary beam models in which $B_{\omega}$ is neglected. For all the six modes, the transverse shear strain energy was found to be negligible (less than 0.6 percent of the total energy).

Figures 5 and 6 give an indication of the accuracy and convergence of the first six frequencies obtained by using the M3-2 and M4-3 models. (See table I.) The standard for comparison was taken to be the two-dimensional-model solution obtained using a $20 \times 12$ grid of M9-4 elements (20 elements along the beam length). As can be seen from figures 5 and 6 , the frequencies predicted by the mixed models were highly accurate and converged rapidly with the increase in the number of elements. Thus, the converged frequencies obtained by the thin-walled beam model were close to those obtained by the twodimensional model. The maximum error in the lowest six frequencies obtained by the converged thinwalled beam models was less than 1 percent.

The effect of the magnitude of the penalty parameter on the accuracy of the lowest six frequencies obtained by the mixed models is depicted in figure 7 . As can be seen, the accuracy of the frequencies obtained by the mixed models is fairly insensitive to the choice of $\varepsilon$ in the range of $\varepsilon / E A$ from $10^{-3}$ to $10^{2}$. The upper limit of $\varepsilon$ is a function of the number of significant digits in the computer.

\section{Semicircular Beams With Z-Sections}

The second problem is that of the clamped semicircular beams with the Z-sections of equal and unequal flanges. (See fig. 8.) Henceforth, the equal and unequal flange sections will be referred to as the "symmetric and unsymmetric Z-sections." Because of the spanwise symmetry of the structure, only half the beam was modeled. The vibration mode shapes associated with the lowest six frequencies for the beam with symmetric Z-section are shown in figure 9. These mode shapes are obtained by the twodimensional model. The ratios of the strain energies $U_{n} / U$ and $U_{\mathrm{ts}} / U$ obtained by the thin-walled beam model for the six vibration modes are shown in figure 10. Again, for all six modes the transverse shear strain energy was found to be less than 0.6 percent of the total energy.

An indication of the accuracy and convergence of the frequencies obtained by the M3-2 and M4-3 models for the beams with symmetric and unsymmetric sections is given in figures 11 and 12 . Although the 
frequencies predicted by the thin-walled beam models converge rapidly with increasing the number of elements, the errors in the converged frequencies obtained by the thin-walled beam model are greater than those for the straight beam described in the previous subsection. The maximum error in the lowest six frequencies for the beam with unsymmetric Z-section was of the order of 7.5 percent. (See fig. 12 and table II.) The accuracy degradation for the beam with unsymmetric Z-section may be attributed to the cross-sectional distortions that are more pronounced in the mode shapes of the semicircular beam than in those of the straight beam.

\section{Concluding Remarks}

Simple, mixed finite element models are developed for the free-vibration analysis of curved, thinwalled beams with arbitrary open cross section. The analytical formulation is based on a linear, Vlasovtype, thin-walled beam theory with the effects of flexural-torsional coupling, transverse shear deformation, and rotary inertia included. The fundamental unknowns consist of seven internal forces and seven generalized displacements of the beam. The element characteristic arrays are obtained by using a modified form of the Hellinger-Reissner mixed variational principle. The modification consists of augmenting the functional of that principle by two terms: (1) the Lagrange multiplier associated with the constraint condition relating the rotation of the cross section and the twist degrees of freedom, and (2) a regularization term that is quadratic in the Lagrange multiplier. Only $\mathrm{C}^{0}$ continuity is required for the generalized displacements. The internal forces and the Lagrange multiplier are allowed to be discontinuous at interelement boundaries.

The high accuracy and effectiveness of the mixed models developed are demonstrated by means of numerical examples of thin-walled beams with symmetric and unsymmetric cross sections. The standard of comparison in these examples is taken to be the solutions obtained by using two-dimensional plate/shell models for the beams. The accuracy of the mixed models developed is dependent on the cross-sectional distortions during the beam deformations. As the cross-sectional distortions increase, the degradation of accuracy becomes more pronounced.

\section{Acknowledgment}

The present research is supported by NASA Grant NAG1-730. The authors appreciate the help of Jeffrey A. Cerro, Planning Research Corporation, Hampton, Virginia, in generating some of the figures, and they acknowledge useful discussions with Huey D. Carden of the NASA Langley Research Center. The numerical results were conducted on the CRAY-2 computer at the NASA Ames Research Center.

NASA Langley Research Center

Hampton, VA 23665-5225

December 15, 1988 


\section{Appendix A}

\section{Fundamental Equations of Thin-Walled Beam Theory Used in Present Study}

The fundamental equations of the linear, Vlasov-type theory of curved thin-walled beams are given in this appendix. A right-handed orthogonal coordinate system is used with the $x$-axis passing through the centroids of the cross sections. (See fig. 1.) The beam is assumed to be curved in one direction only (in the $x z$-plane).

\section{Displacement Assumptions}

Based on the assumption that the projection of each cross section on a plane normal to the initial centroidal axes does not distort during deformation, the displacement field in the plane of the cross section ( $y z$-plane) is represented by

$$
\left\{\begin{array}{c}
u(x, y, z) \\
v(x, y, z) \\
w(x, y, z)
\end{array}\right\}=\left\{\begin{array}{c}
u^{0} \\
v^{0} \\
w^{0}
\end{array}\right\}+\left[\begin{array}{ccc}
\cdot & z & -y \\
-z & \cdot & \cdot \\
y & \cdot & \cdot
\end{array}\right]\left\{\begin{array}{c}
\phi_{x}^{0} \\
\phi_{y}^{0} \\
\phi_{z}^{0}
\end{array}\right\}-\left\{\begin{array}{l}
\omega \\
\cdot \\
\cdot
\end{array}\right\} \theta^{0}
$$

where $u^{0}, v^{0}$, and $w^{0}$ are the axial and transverse displacement components at $y=z=0 ; \phi_{x}^{0}, \phi_{y}^{0}$, and $\phi_{z}^{0}$ are the rotation components about the coordinate axes; $\theta^{0}$ is the rate of twist of the beam; and $\omega$ is the sectorial coordinate (warping of the cross section for a unit rate of twist). The seven generalized displacement parameters $u^{0}, v^{0}, w^{0}, \phi_{x}^{0}, \phi_{y}^{0}, \phi_{z}^{0}$, and $\theta^{0}$ are functions of $x$ only.

\section{Strain Assumptions}

The following expressions are used for the three nonzero components of the strain field in the plane of the cross section:

$$
\left.\begin{array}{rl}
\varepsilon_{x} & =\varepsilon_{x}^{0}-y \kappa_{y}^{0}+z \kappa_{z}^{0}-\omega \psi^{0} \\
\gamma_{x y} & =\gamma_{x y}^{0}-z \kappa_{t}^{0} \\
\gamma_{x z} & =\gamma_{x z}^{0}+y \kappa_{t}^{0}
\end{array}\right\}
$$

where $\varepsilon_{x}^{0}$ is the extensional strain of the centerline; $\kappa_{y}^{0}$ and $\kappa_{z}^{0}$ are the curvature changes in the $y$ - and $z$ directions, respectively; $\kappa_{t}^{0}$ is the twist; and $\gamma_{x y}^{0}$ and $\gamma_{x z}^{0}$ are the transverse shear strains. The strain parameters $\varepsilon_{x}^{0}, \kappa_{y}^{0}, \kappa_{z}^{0}, \gamma_{x z}^{0}, \gamma_{x y}^{0}, \kappa_{t}^{0}$, and $\psi^{0}$ are functions of $x$ only and can be expressed in terms of the displacement and rotation components as follows:

$$
\begin{aligned}
\varepsilon_{x}^{0} & =\partial u^{0}+\frac{w^{0}}{R} \\
\kappa_{y}^{0} & =\partial \phi_{z}^{0}-\frac{\phi_{x}^{0}}{R} \\
\kappa_{z}^{0} & =\partial \phi_{y}^{0} \\
\gamma_{x y}^{0} & =\partial v^{0}-\phi_{z}^{0} \\
\gamma_{x z}^{0} & =-\frac{u^{0}}{R}+\partial w^{0}+\phi_{y}^{0} \\
\kappa_{t}^{0} & =\partial \phi_{x}^{0}+\frac{\phi_{z}^{0}}{R} \\
\psi^{0} & =\partial \theta^{0}
\end{aligned}
$$

where $\partial \equiv d / d x$ and $R$ is the radius of curvature of the centerline of the beam. Also, the following constraint condition is used to relate $\theta^{0}$ and $\phi_{x}^{0}$ :

$$
\partial \phi_{x}^{0}-\theta^{0}=0
$$




\section{Constitutive Relations}

The relations between the internal forces and the strain components are given by

$$
\left\{\begin{array}{l}
N_{x} \\
M_{z} \\
M_{y} \\
B_{\omega}
\end{array}\right\}=\int_{A} \sigma_{x}\left\{\begin{array}{c}
1 \\
-y \\
z \\
\omega
\end{array}\right\} d A=E\left[\begin{array}{cccc}
A & \cdot & \cdot & -S_{\omega} \\
& I_{z} & -I_{y z} & I_{\omega z} \\
& & I_{y} & -I_{\omega y} \\
\text { Symm } & & & I_{\omega}
\end{array}\right]\left\{\begin{array}{c}
\varepsilon_{x}^{0} \\
\kappa_{y}^{0} \\
\kappa_{z}^{0} \\
\psi^{0}
\end{array}\right\}
$$

and

$$
\left\{\begin{array}{l}
Q_{y} \\
Q_{z} \\
M_{t}
\end{array}\right\}=\int_{A}\left[\begin{array}{cc}
1 & \cdot \\
\cdot & 1 \\
-z & y
\end{array}\right]\left\{\begin{array}{l}
\sigma_{x y} \\
\sigma_{x z}
\end{array}\right\} d A=G\left[\begin{array}{ccc}
A_{y} & \cdot & \cdot \\
\cdot & A_{z} & \cdot \\
\cdot & \cdot & J
\end{array}\right]\left\{\begin{array}{c}
\gamma_{x y}^{0} \\
\gamma_{x z}^{0} \\
\kappa_{t}^{0}
\end{array}\right\}
$$

where $A$ is the cross-sectional area; $S_{\omega}$ is the first sectorial moment of the cross section; $I_{y}, I_{z}$, and $I_{y z}$ are the second moments of the cross section (moments and product of inertia); $J$ is the Saint-Venant torsion constant; $I_{\omega}, I_{\omega y}$, and $I_{\omega z}$ are the second sectorial moments of the cross section (sectorial moments of inertia); $E$ and $G$ are the Young's and shear moduli of the material, respectively; $N_{x}$ is the axial force; $M_{y}$ and $M_{z}$ are the bending moments; $B_{\omega}$ is the bimoment; $Q_{y}$ and $Q_{z}$ are the transverse shearing forces; and $M_{t}$ is the twisting moment. The definition of the sectorial properties of the cross section is given by Friberg (1985), Heins and Wang (1978), Vlasov (1961), and Zbirohowski-Kos̀cia (1967).

\section{Variational Functional}

The functional used in the element development is given by

$$
\pi=\pi_{\mathrm{HR}}+\int_{0}^{l} \bar{\lambda}\left(\partial \phi_{x}^{0}-\theta^{0}\right) d x-\frac{1}{2 \varepsilon} \int_{0}^{l}(\bar{\lambda})^{2} d x
$$

where $\bar{\lambda}$ is the Lagrange multiplier, $\varepsilon$ is a penalty parameter, $l$ is the length of the element, and $\pi_{\mathrm{HR}}$ is the functional of the Hellinger-Reissner mixed variational principle. The expression for $\pi_{\mathrm{HR}}$ is

where

$$
\pi_{\mathrm{HR}}=\int_{0}^{l}\left(V-U^{c}+K\right) d x
$$

$$
\begin{aligned}
& V=\left\{\begin{array}{c}
N_{x} \\
M_{z} \\
M_{y} \\
B_{\omega}
\end{array}\right\}^{t}\left\{\begin{array}{c}
\varepsilon_{x}^{0} \\
\kappa_{y}^{0} \\
\kappa_{z}^{0} \\
\psi^{0}
\end{array}\right\}+\left\{\begin{array}{l}
Q_{y} \\
Q_{z} \\
M_{t}
\end{array}\right\}\left\{\begin{array}{c}
\gamma_{x y}^{0} \\
\gamma_{x z}^{0} \\
\kappa_{t}^{0}
\end{array}\right\} \\
& U^{c}=\frac{1}{2 E}\left\{\begin{array}{l}
N_{x} \\
M_{z} \\
M_{y} \\
B_{\omega}
\end{array}\right\}^{t}\left[\begin{array}{cccc}
A & \cdot & \cdot & -S_{\omega} \\
& I_{z} & -I_{y z} & I_{\omega z} \\
& & I_{y} & -I_{\omega y} \\
& & & \\
& & & I_{\omega}
\end{array}\right]^{-1}\left\{\begin{array}{l}
N_{x} \\
M_{z} \\
M_{y} \\
B_{\omega}
\end{array}\right\} \\
& +\frac{1}{2 G}\left\{\begin{array}{l}
Q_{y} \\
Q_{z} \\
M_{t}
\end{array}\right\}^{t}\left[\begin{array}{ccc}
\frac{1}{A_{y}} & \cdot & \cdot \\
& \frac{1}{A_{z}} & \cdot \\
\text { Symm } & & \frac{1}{J}
\end{array}\right]\left\{\begin{array}{l}
Q_{y} \\
Q_{z} \\
M_{t}
\end{array}\right\}
\end{aligned}
$$




$$
\begin{aligned}
K= & \frac{\rho}{2} \Omega^{2}\left\{A\left[\left(u^{0}\right)^{2}+\left(v^{0}\right)^{2}+\left(w^{0}\right)^{2}\right]+\left(I_{y}+I_{z}\right)\left(\phi_{x}^{0}\right)^{2}+I_{y}\left(\phi_{y}^{0}\right)^{2}+I_{z}\left(\phi_{z}^{0}\right)^{2}-2 I_{y z} \phi_{y}^{0} \phi_{z}^{0}\right. \\
& \left.+2\left(S_{\omega} u^{0}-I_{\omega y} \phi_{y}^{0}+I_{\omega z} \phi_{z}^{0}\right) \theta^{0}+I_{\omega}\left(\theta^{0}\right)^{2}\right\}
\end{aligned}
$$

where $\rho$ is the mass density of the material. Note in equations (A5) through (A10) that $y$ and $z$ are centroidal coordinates. (See fig. 1.) The sectorial properties of the cross section are evaluated using the centroid as the pole and the origin of the contour coordinates $\zeta$ as the lower free end of the cross section. (See fig. 1.) A FORTRAN program for evaluating the sectorial properties is listed by Coyette (1987). 


\section{Appendix B}

\section{Formulas for Coefficients in Governing Equations for Individual Elements}

The explicit forms of the elemental arrays $[F],[S],[P],[Q]$, and $[M]$ are given in this appendix. For convenience, each of these arrays is partitioned into blocks according to contributions from individual nodes, internal forces, or Lagrange multiplier parameters. The expressions of the typical partitions (or blocks) are given in table BI. Note that the order of internal force parameters is $N_{x}, M_{z}, M_{y}, B_{\omega}, Q_{y}, Q_{z}$, and $M_{t}$; the order of the generalized displacement coefficients is $u^{0}, v^{0}, w^{0}, \phi_{x}^{0}, \phi_{y}^{0}, \phi_{z}^{0}$, and $\theta^{0}$.

In table BI, $\bar{N}^{i}$ and $\bar{N}^{j}$ are the shape functions for both the internal forces and the Lagrange multiplier; $N^{j}$ represents the shape functions for the generalized displacements; $R$ is the radius of curvature; $\mathrm{m}$ is the number of displacement nodes in the element; $[I]$ is the identity submatrix; $s$ is the number of parameters used in approximating each of the internal forces and the Lagrange multiplier; $l$ is the length of the element; and $\partial \equiv d / d x$. The range of the indices $i$ and $j$ is 1 to $s$, and the range of the indices $\mathrm{i}$ and $\mathrm{j}$ is 1 to $\mathrm{m}$. The dots in the matrices refer to zero terms.

Table BI. Explicit Form of Typical Partitions of the Arrays $[F],[S],[P],[Q]$, and $[M]$

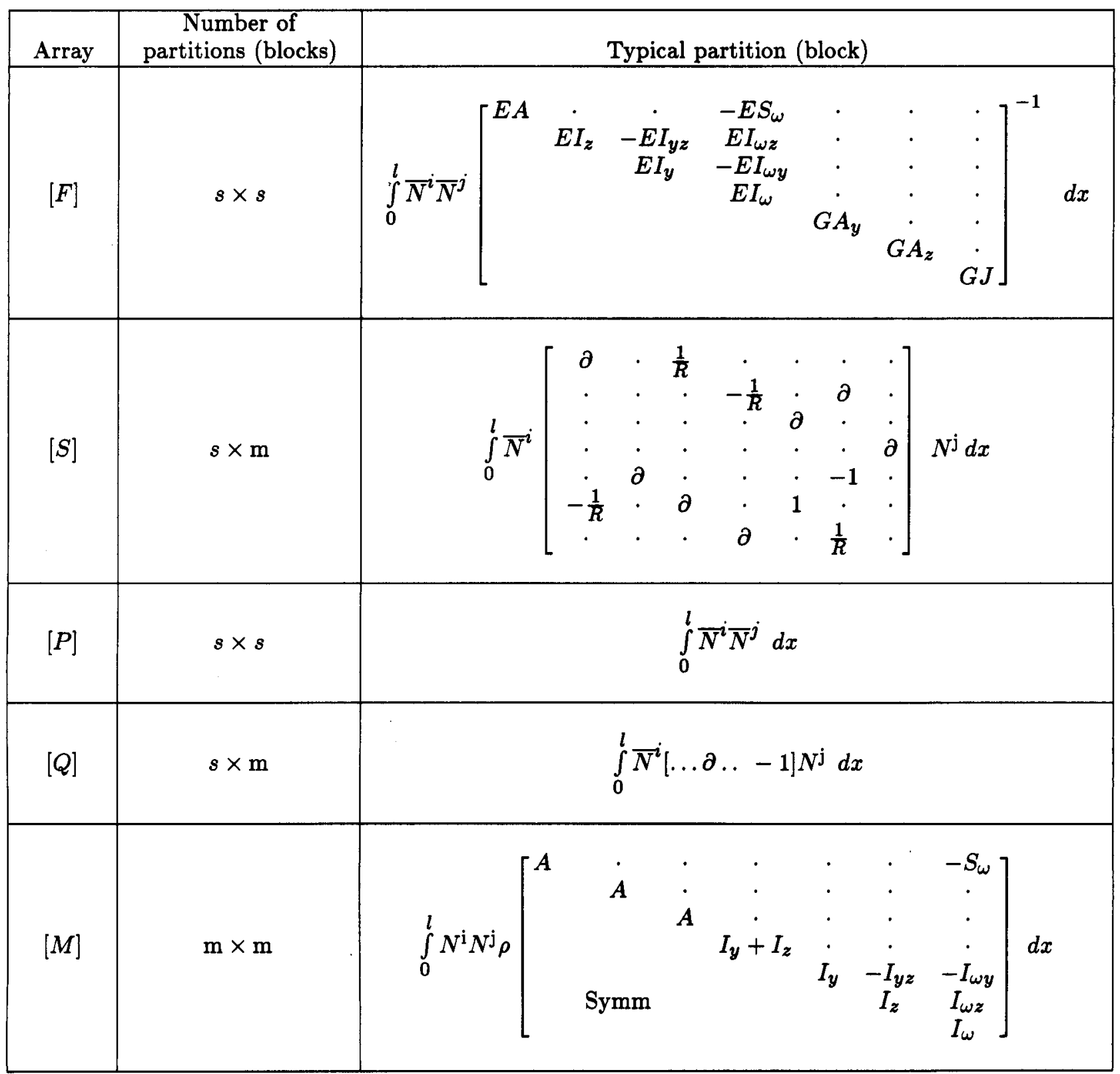




\section{References}

Attard, Mario M.: Lateral Buckling Analysis of Beams by the FEM. Comput. $\&$ Struct., vol. 23, no. 2, 1986, pp. 217-231.

Barsoum, Roshdy S.; and Gallagher, Richard H.: Finite Element Analysis of Torsional and TorsionalFlexural Stability Problems. Int. J. Numer. Methods Eng., vol. 2, no. 3, July-Sept. 1970, pp. 335-352.

Coyette, J. P.: An Improved Subroutine for the Estimation of Torsional Properties of Thin Walled Open Cross-Sections. Eng. Comput., vol. 4, no. 3, Sept. 1987, pp. 240-242.

Epstein, Marcelo; and Murray, David W.: ThreeDimensional Large Deformation Analysis of Thin Walled Beams. Int. J. Solids \& Struct., vol. 12, no. 12, 1976, pp. 867-876.

Fortin, Michel; and Glowinski, Roland: Augmented Lagrangian Methods: Applications to the Numerical Solution of Boundary-Value Problems. NorthHolland, 1983.

Friberg, P. O.: Beam Element Matrices Derived From Vlasov's Theory of Open Thin-Walled Elastic Beams. Int. J. Numer. Methods Eng., vol. 21, no. 7, July 1985, pp. 1205-1228.

Gere, J. M.; and Lin, Y. K.: Coupled Vibrations of Thin-Walled Beams of Open Cross Section. $J$. Appl. Mech., vol. 25, no. 3, Sept. 1958, pp. 373-378.

Gjelsvik, Atle: The Theory of Thin Walled Bars. John Wiley \& Sons, Inc., c.1981.

Heins, C. P.; and Wang, R. C.: Torsional Properties of Open Cross Sections. Comput. \& Struct., vol. 9, no. 6 , Nov. 1978 , pp. $495-500$.

Kiss, Ferenc: The New Family of General Beam Elements for ASKA-Theoretical Manual. IKO Software Service $\mathrm{GmbH}$ (Stuttgart), 1986.

Kollbrunner, C. F.; and Basler, K. (E. C. Glauser, transl., and Annotations and Appendix by B. G. Johnston): Torsion in Structures-An Engineering Approach. Springer-Verlag, 1969.

Krajcinovic, Dusan: A Consistent Discrete Elements Technique for Thinwalled Assemblages. Int. J. Solids \& Struct., vol. 5, no. 7, July 1969, pp. 639-662.
Mei, Chuh: Coupled Vibrations of Thin-Walled Beams of Open Section Using the Finite Element Method. Int. J. Mech. Sci., vol. 12, no. 10, Oct. 1970, pp. 883-891.

Noor, Ahmed K.; and Andersen, C. M.: Mixed Models and Reduced/Selective Integration Displacement Models for Nonlinear Shell Analysis. Int. J. Numer. Methods Eng., vol. 18, no. 10, Oct. 1982, pp. 1429-1454.

Noor, Ahmed K.; and Peters, Jeanne M.: Mixed Models and Reduced Selective Integration Displacement Models for Vibration Analysis of Shells. Hybrid and Mixed Finite Element Methods, S. N. Atluri, R. H. Gallagher, and O. C. Zienkiewicz, eds., John Wiley \& Sons Ltd., c.1983, pp. 537-564.

Nowinski, J. L.: Theory of Thin-Walled Bars. Applied Mechanics Surveys, H. Norman Abramson, Harold Liebowitz, John M. Crowley, and Stephen Juhasz, eds., Spartan Books, 1966, pp. 325-338.

Panovko, Ya. G.; and Beilin, E. A.: Thin-Walled Beams and Systems Consisting of Thin-Walled Beams. Structural Mechanics in the USSR-19171967, I. M. Rabinovich, ed., Moscow Publ. House, 1969, pp. 75-98. (In Russian.)

Rozmarynowski, B.; and Szymczak, C.: Non-Linear Free Torsional Vibrations of Thin-Walled Beams With Bisymmetric Cross-Section. J. Sound $\&$ Vibration, vol. 97, no. 1, Nov. 8, 1984, pp. 145-152.

Tralli, A.: A Simple Hybrid Model for Torsion and Flexure of Thin-Walled Beams. Comput. \& Struct., vol. 22, no. 4, 1986, pp. 649-658.

Vlasov, V. Z. (Y. Schechtman, transl.): Thin-Walled Elastic Beams. Israel Program for Scientific Translations, 1961.

Washizu, Kyuichiro: Variational Methods in Elasticity and Plasticity, Second ed. Pergamon Press Inc., c. 1974 .

Wekezer, Jerzy W.: Free Vibrations of Thin-Walled Bars With Open Cross Sections. J. Eng. Mech., vol. 113, no. 10, Oct. 1987, pp. 1441-1453.

Zbirohowski-Kos̀cia, K.: Thin Walled Beams-From Theory to Practice. Crosby Lockwood \& Son Ltd., 1967. 
Table I. Characteristics of Mixed Finite Element Models Used in Numerical Studies

\begin{tabular}{|c|c|c|c|c|}
\hline Model & $\begin{array}{c}\text { Number of } \\
\text { displacement } \\
\text { nodes }\end{array}$ & $\begin{array}{c}\text { Number of parameters } \\
\text { per internal force } \\
\text { (or Lagrange multiplier) }\end{array}$ & $\begin{array}{c}\text { Number of } \\
\text { quadrature } \\
\text { points }\end{array}$ & Designation \\
\hline One-dimensional & 3 & 2 & 3 & M3-2 \\
& 4 & 3 & 4 & M4-3 \\
\hline Two-dimensional & 9 & 4 & 9 & M9-4 \\
\hline
\end{tabular}

Table II. Minimum Frequencies Obtained by Two-Dimensional and Thin-Walled Beam (Converged) Models for the Cantilever

Beam With Unsymmetric Channel Section (Fig. 2) and the

Semicircular Beam With Unsymmetric Z-Section (Fig. 8)

\begin{tabular}{|c|c|c|c|c|}
\hline \multirow{2}{*}{ Mode } & \multicolumn{2}{|c|}{$\begin{array}{c}\text { Minimum frequencies } \\
\text { for cantilever beam, } \mathrm{Hz}\end{array}$} & \multicolumn{2}{c|}{$\begin{array}{c}\text { Minimum frequencies } \\
\text { for semicircular beam, } \mathrm{Hz}\end{array}$} \\
\cline { 2 - 5 } & $\Omega_{2 \mathrm{~d}}$ & $\Omega_{\text {converged }}$ & $\Omega_{2 \mathrm{~d}}$ & $\Omega_{\text {converged }}$ \\
\hline 1 & 11.64 & 11.66 & 12.14 & 12.48 \\
2 & 19.64 & 19.67 & 23.12 & 23.08 \\
3 & 40.94 & 41.09 & 44.14 & 42.71 \\
4 & 58.52 & 58.97 & 50.90 & 50.88 \\
5 & 103.6 & 103.9 & 92.71 & 91.42 \\
6 & 113.9 & 114.6 & 100.2 & 92.71 \\
\hline
\end{tabular}




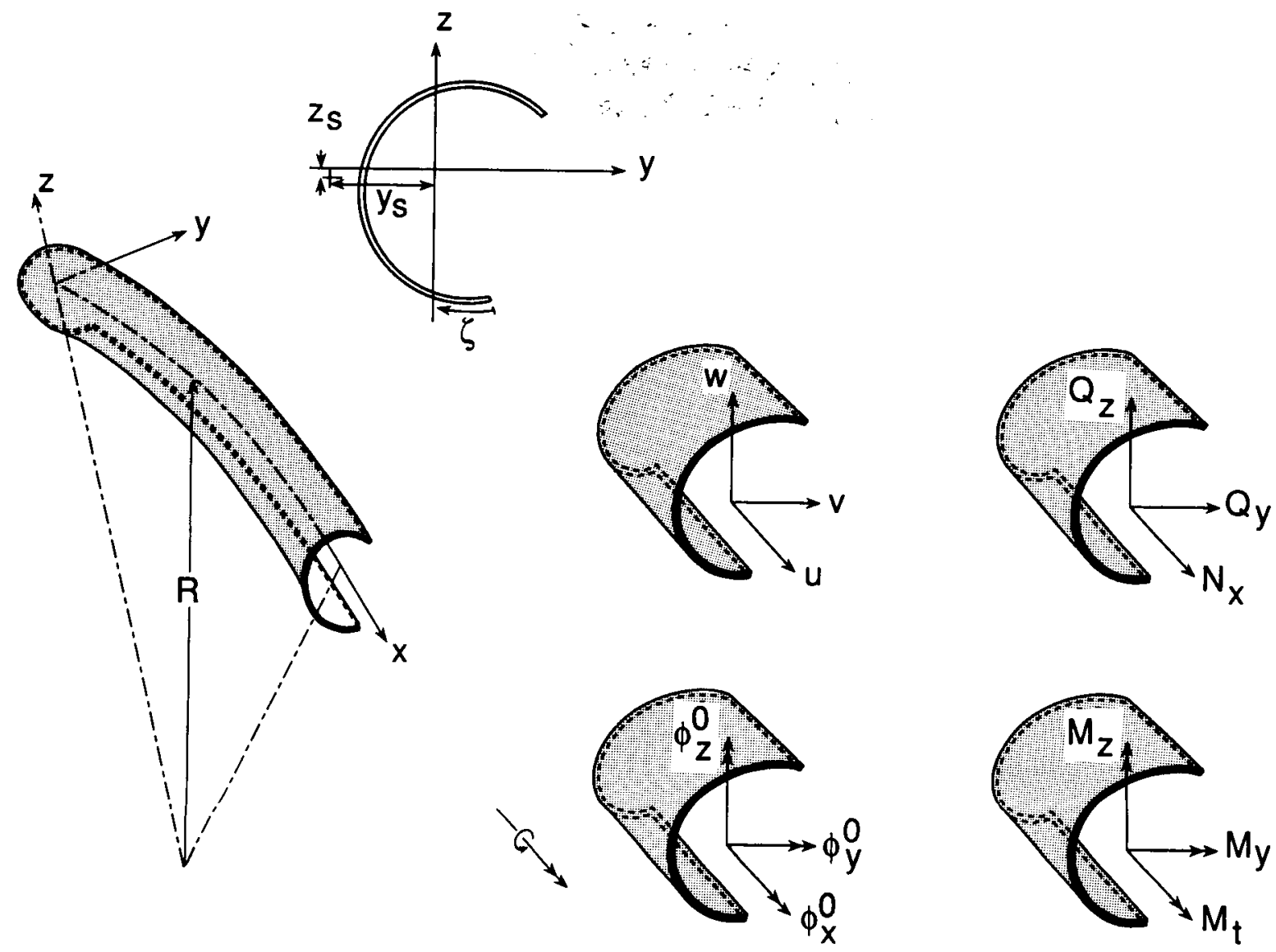

Figure 1. Characteristics of thin-walled beam and sign convention for internal forces and displacements.
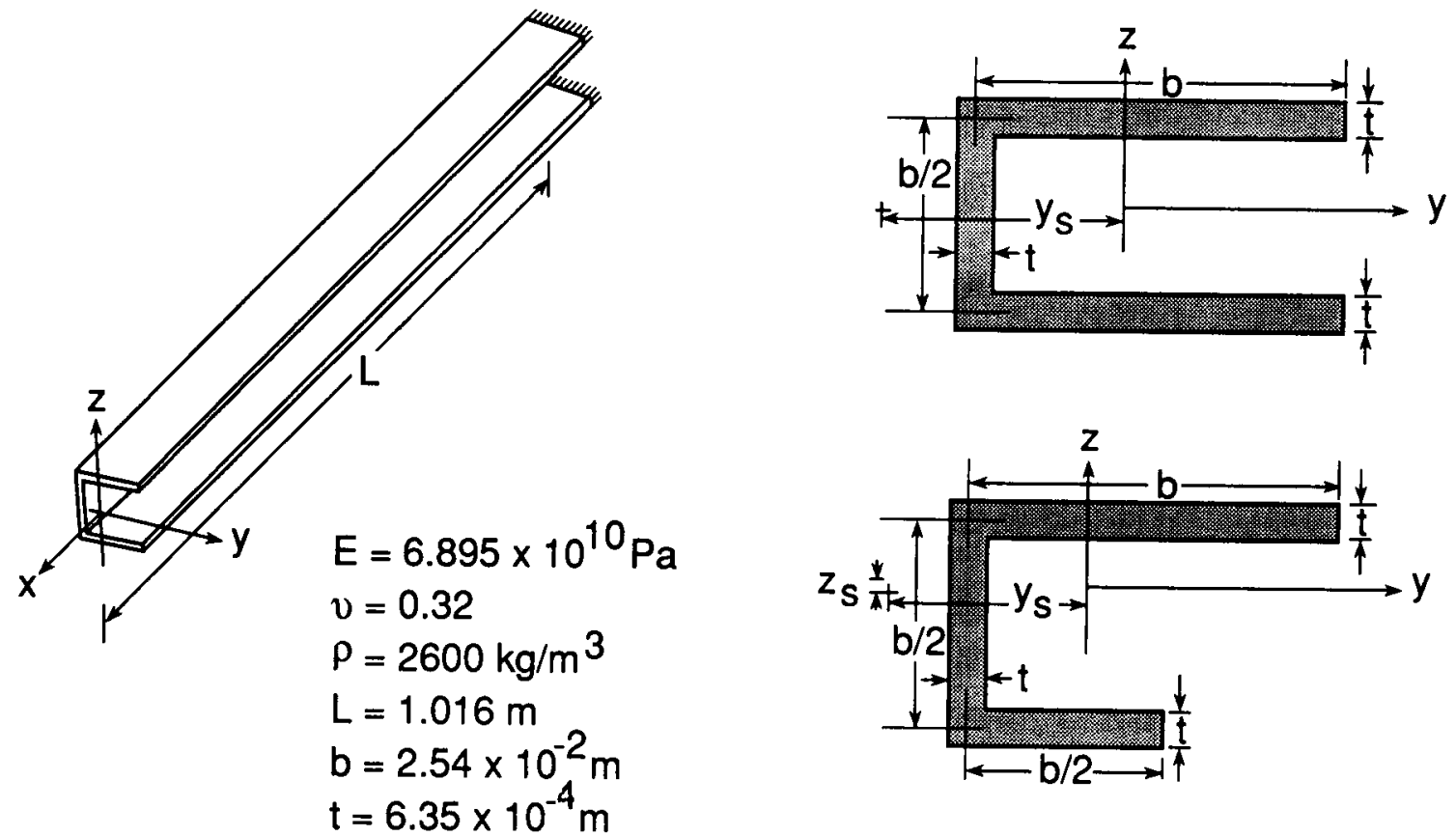

Figure 2. Cantilever beams with channel cross sections used in present study. The subscript $\mathrm{s}$ refers to shear center. 


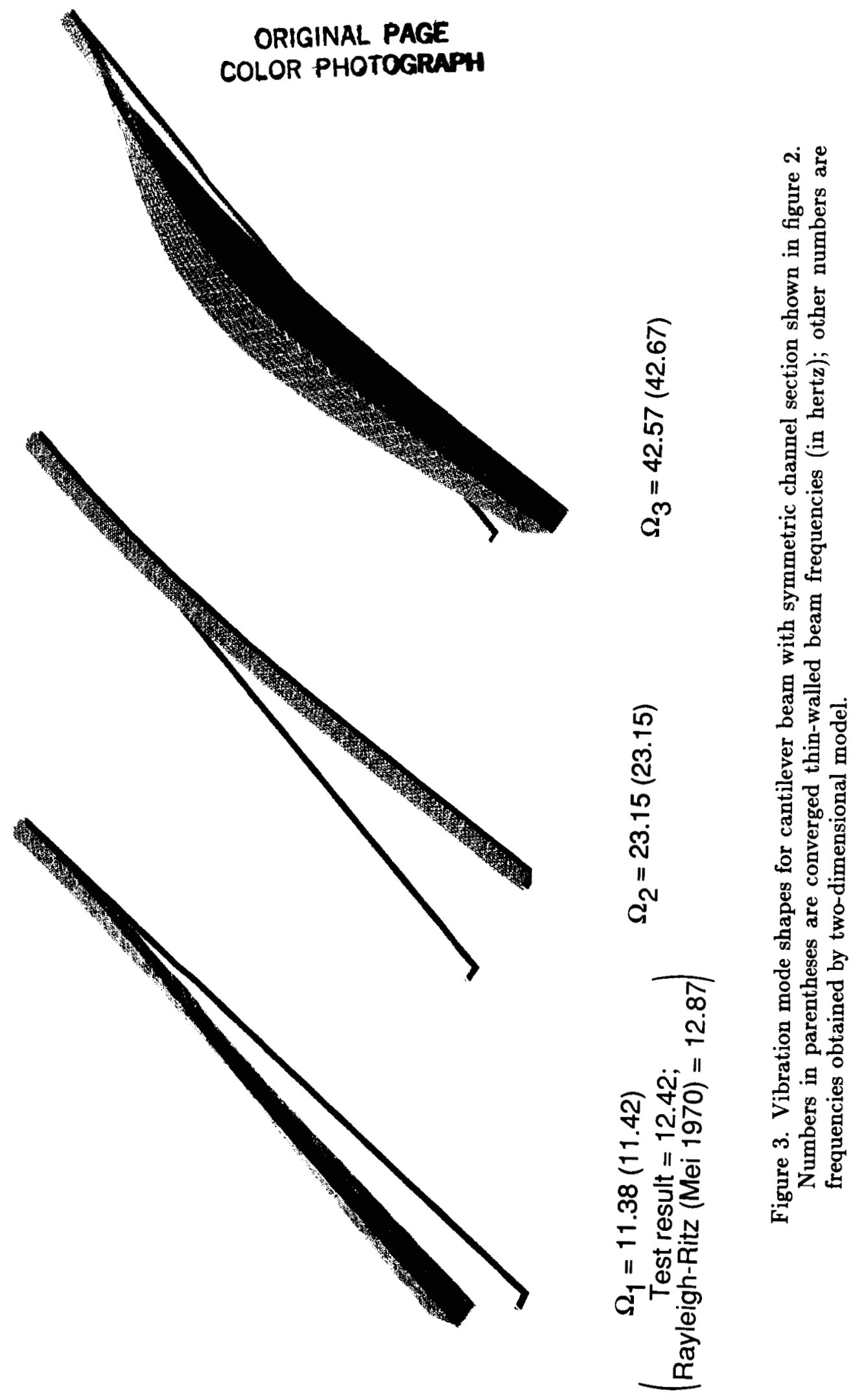




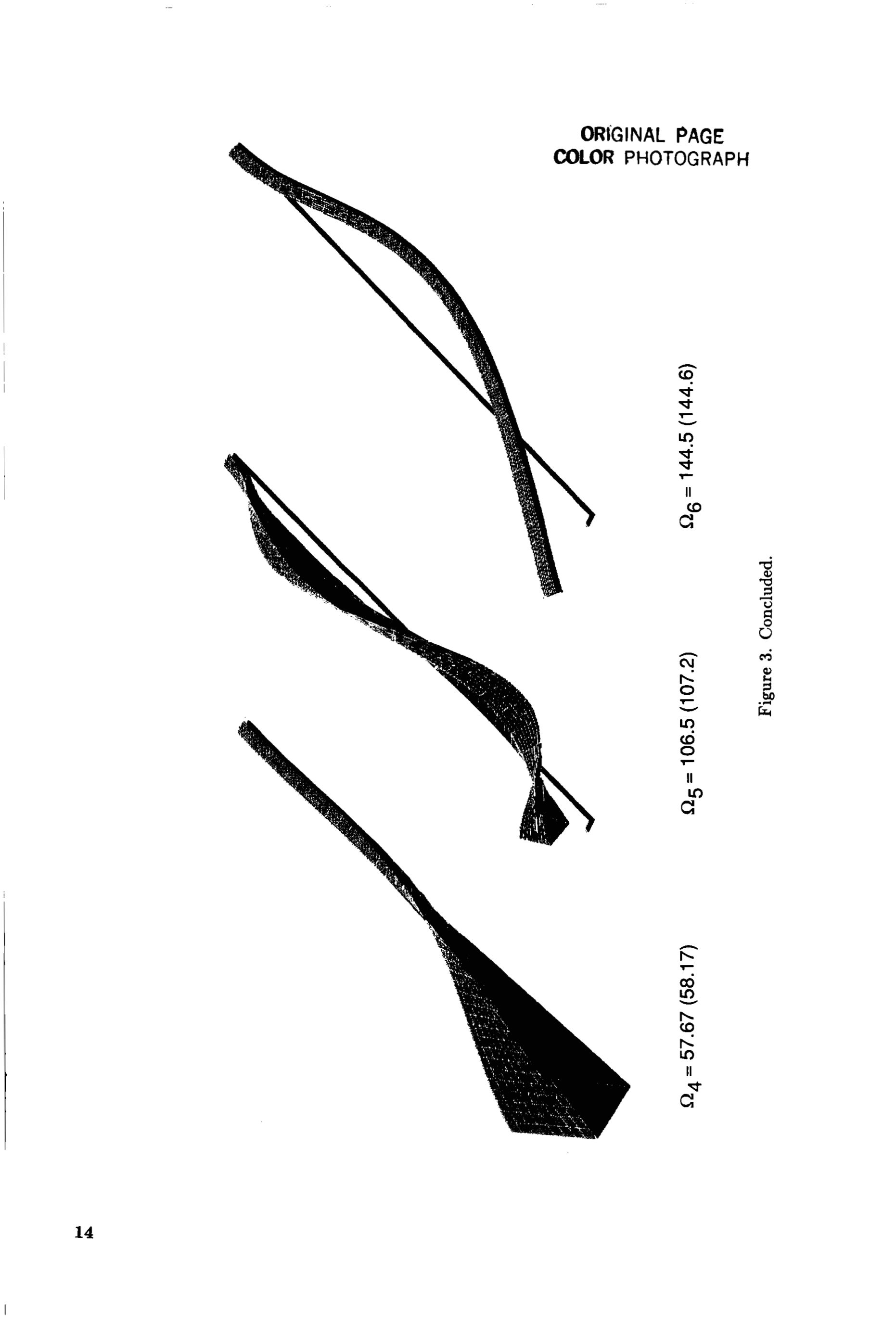



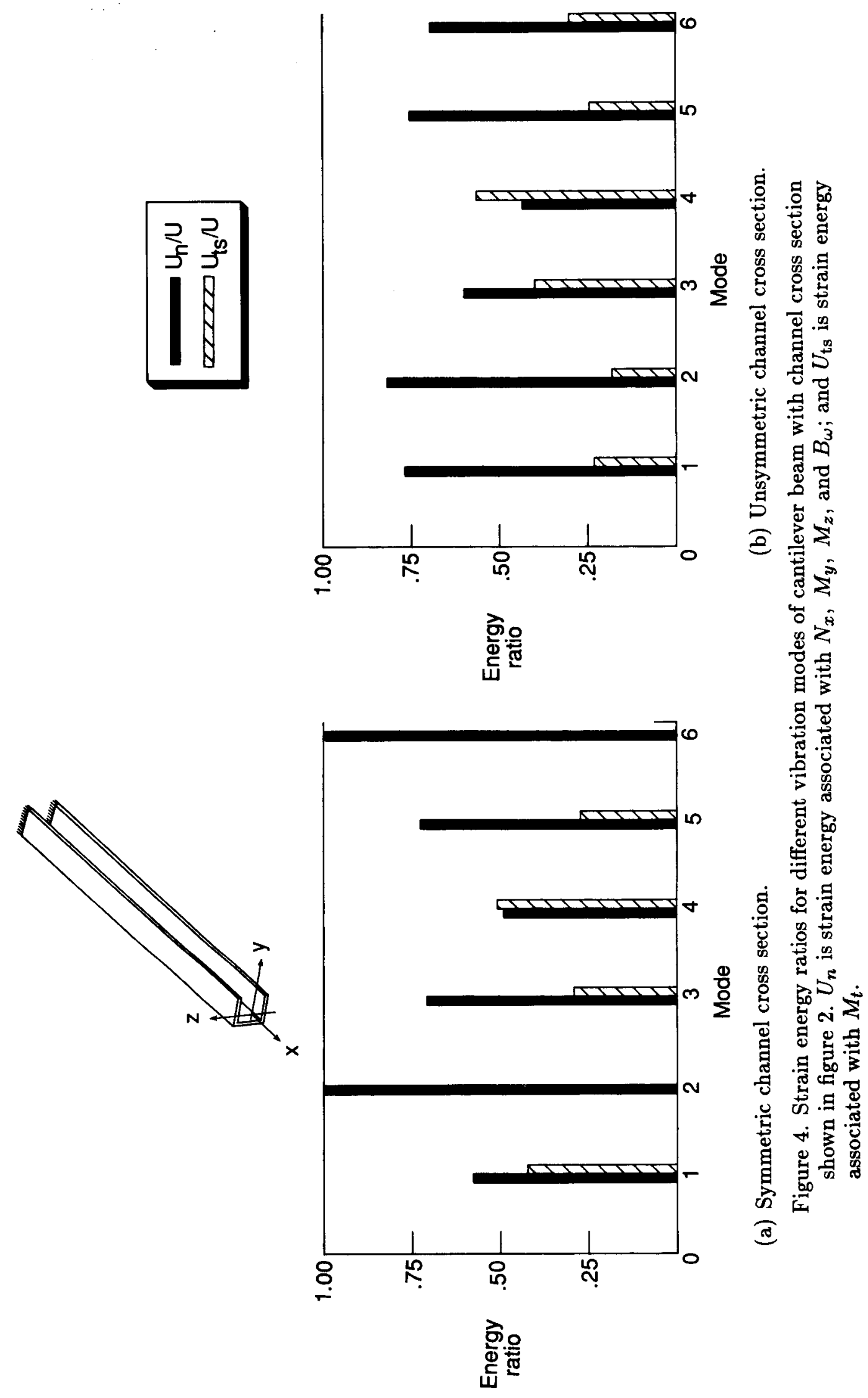


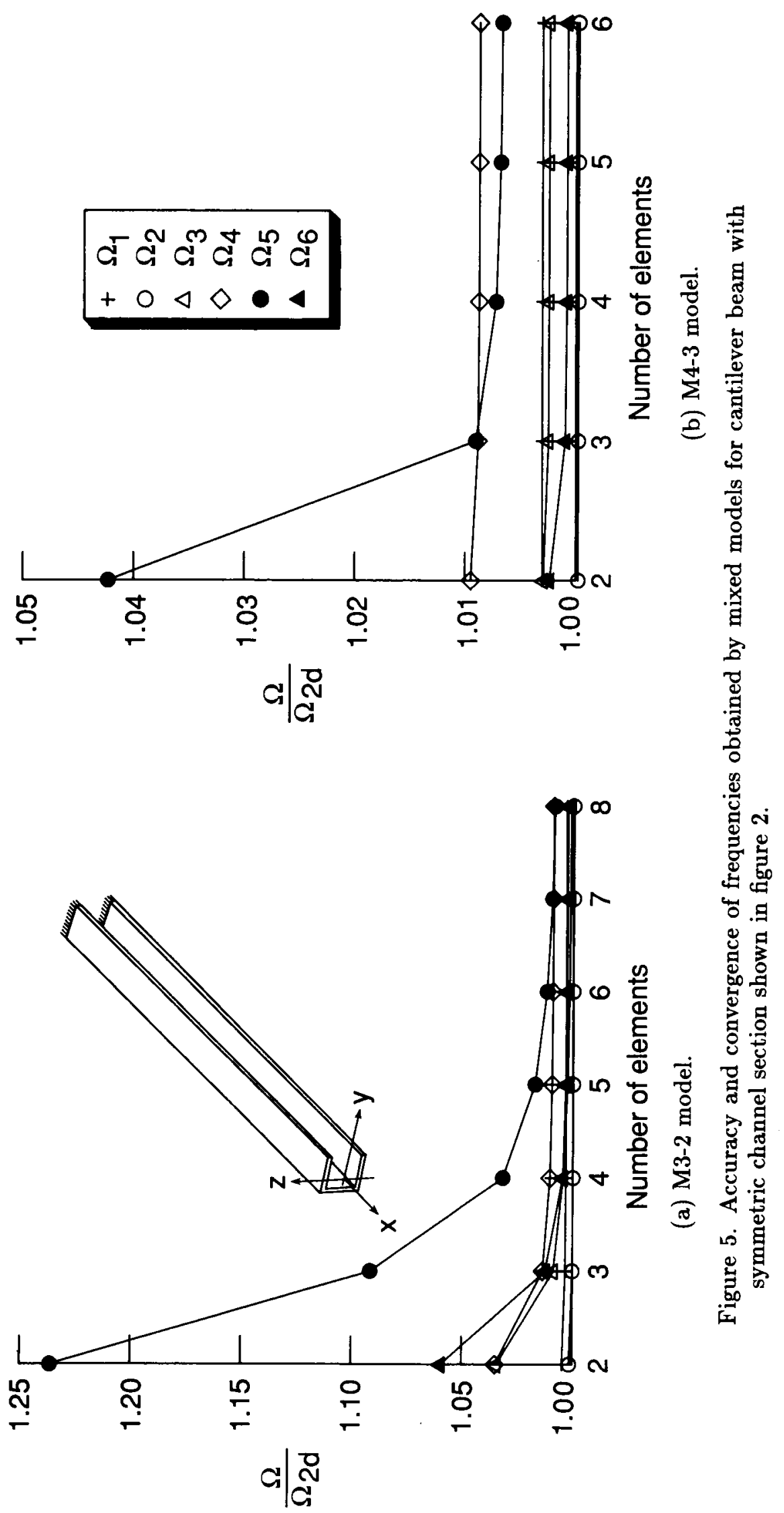



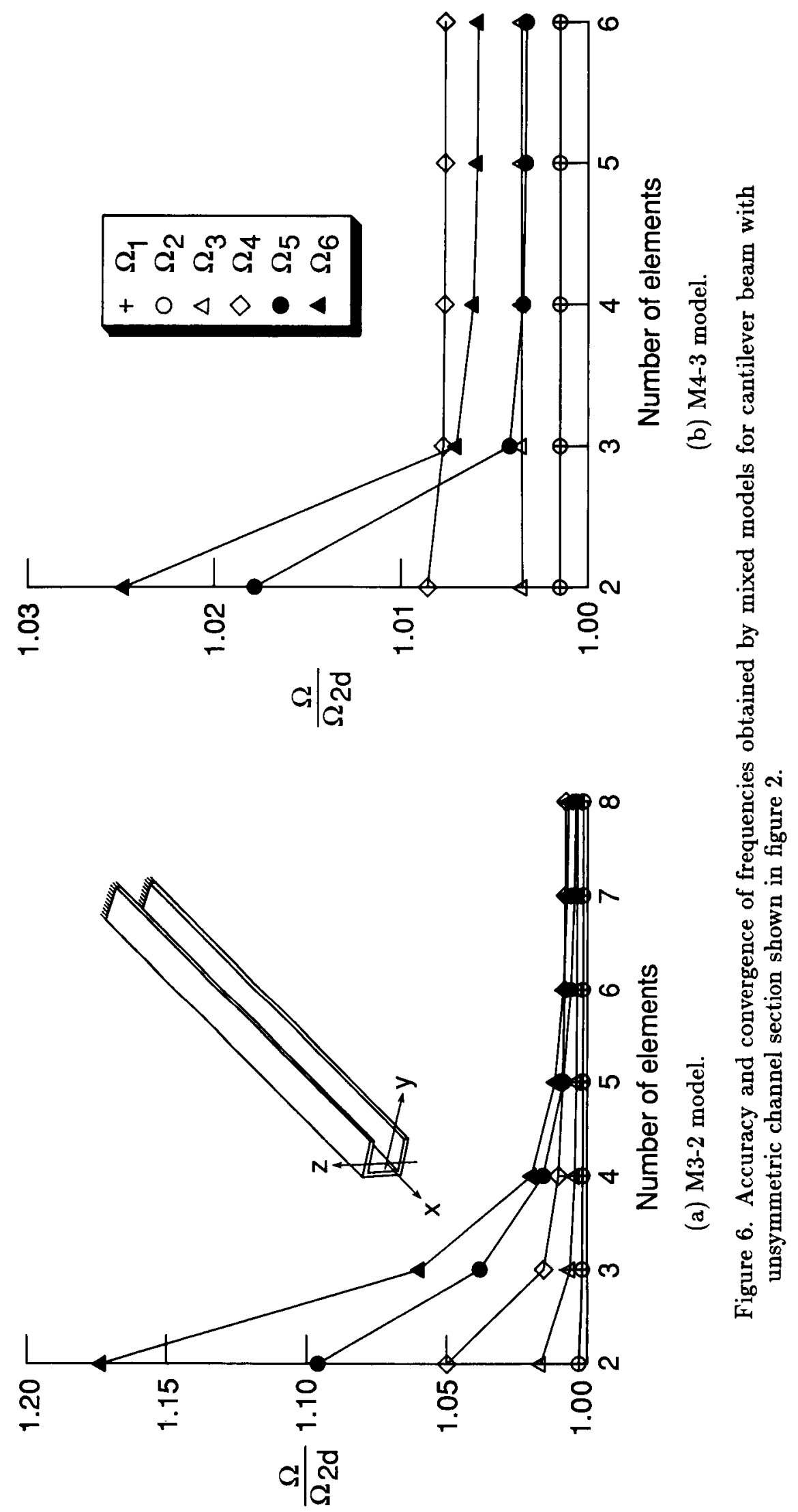


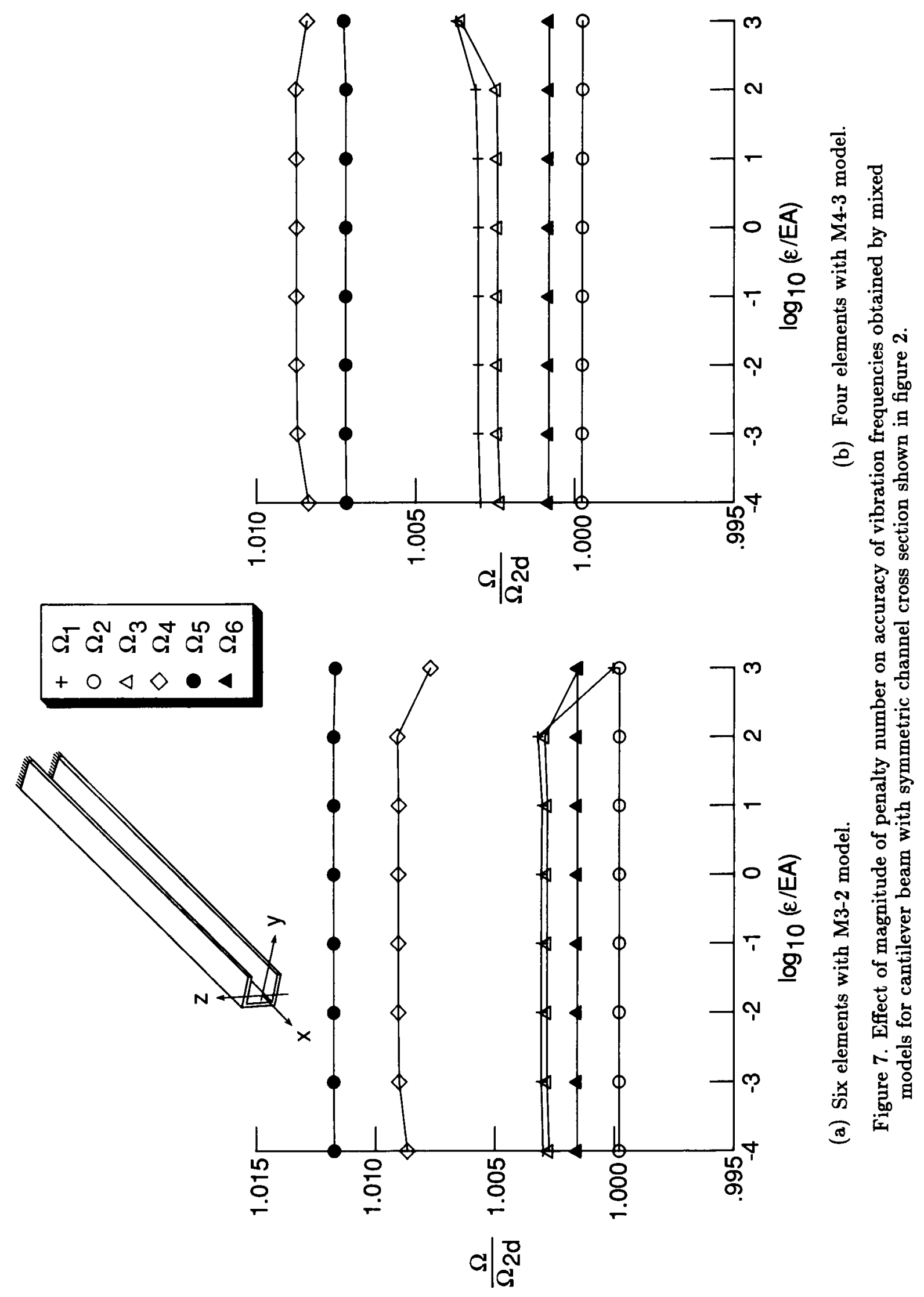




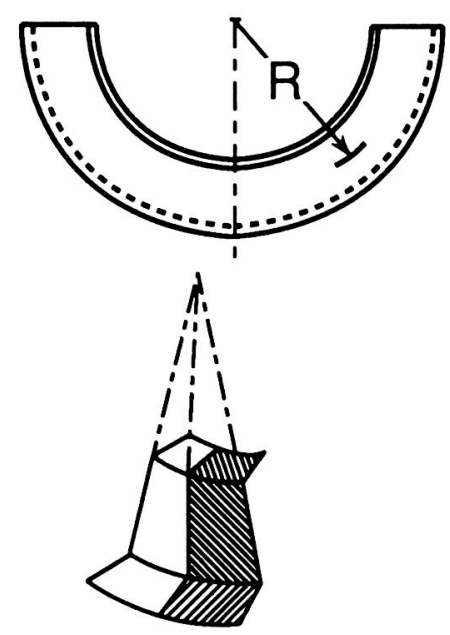

$\mathrm{E}=7.17 \times 10^{10} \mathrm{~Pa}$

$v=0.3$

$\rho=2768 \mathrm{~kg} / \mathrm{m}^{3}$

$\mathrm{R}=1.0 \mathrm{~m}$

$b=5.08 \times 10^{-2} \mathrm{~m}$

$t=6.0 \times 10^{-3} \mathrm{~m}$

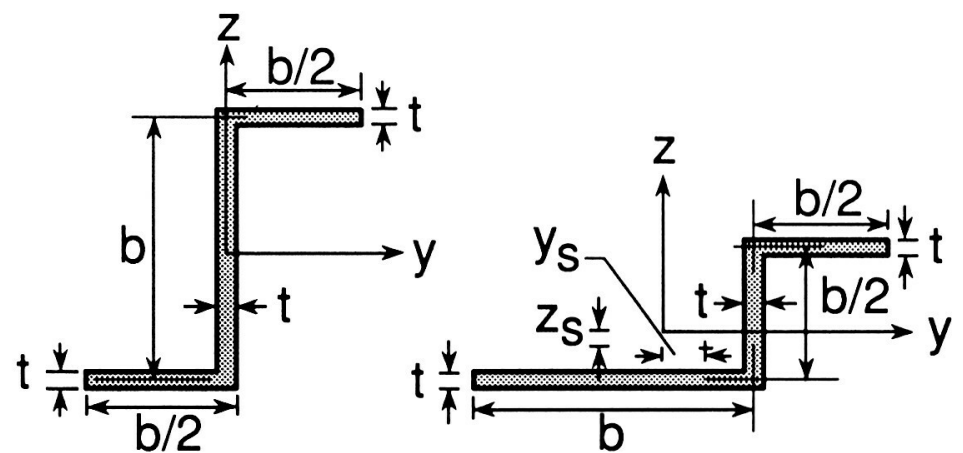

Symmetric section
Unsymmetric section

Figure 8. Semicircular beams with Z-sections used in present study. The subscript s refers to shear center. 


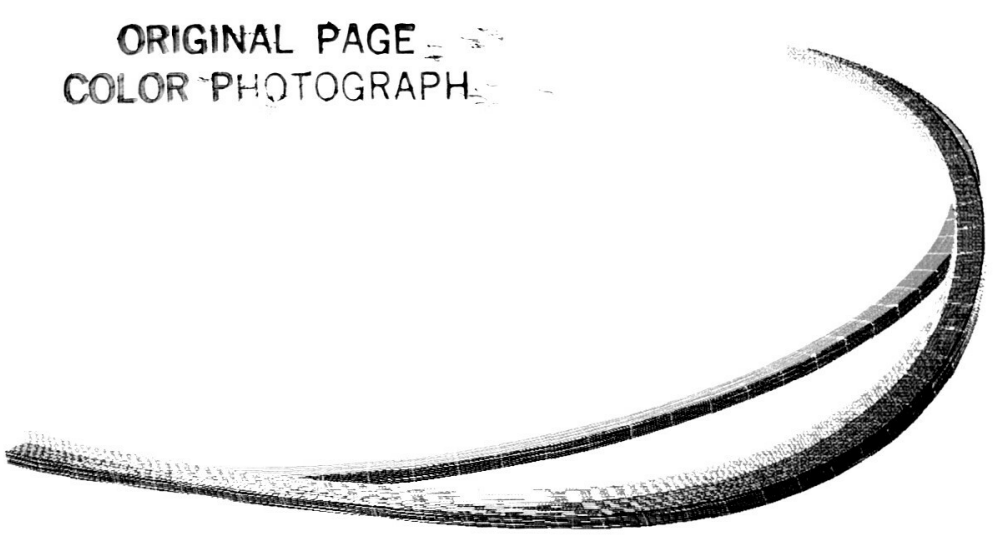

$\Omega_{1}=10.70(11.10)$

$\Omega_{2}=24.02(24.17)$

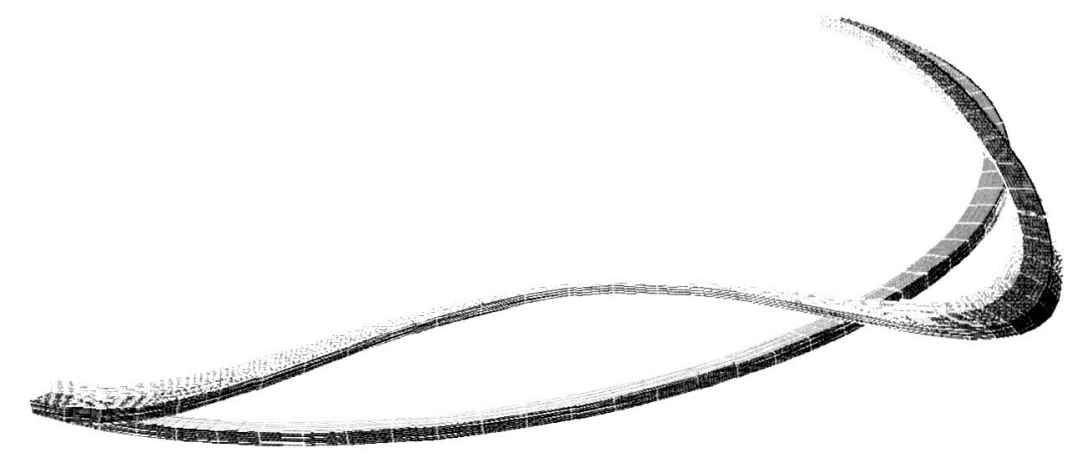

$\Omega_{3}=51.72(52.13)$

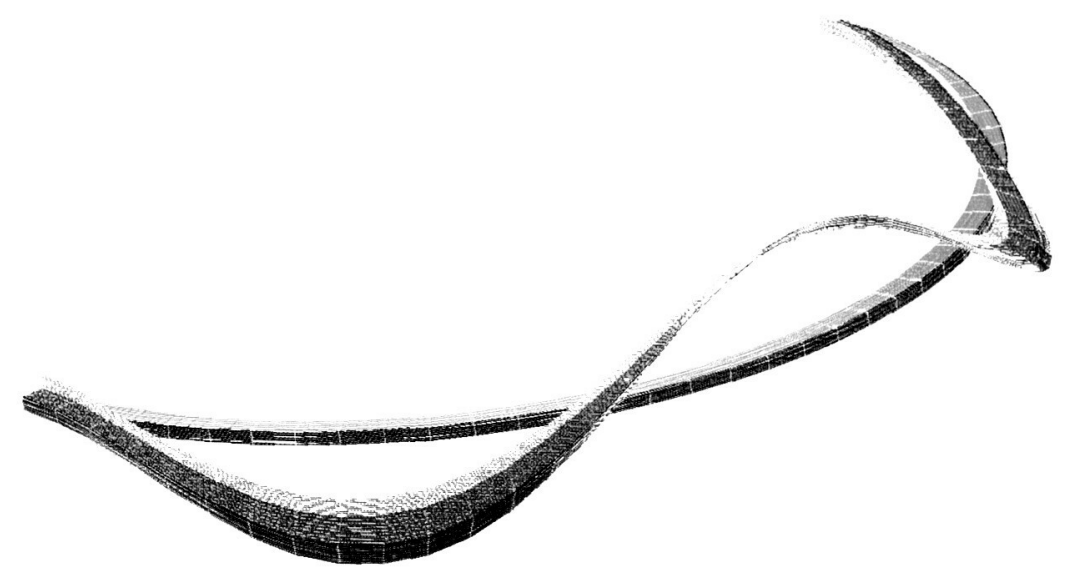

Figure 9. Vibration mode shapes for semicircular beam with symmetric Z-section shown in figure 8. Numbers in parentheses are converged thin-walled beam frequencies (in hertz); other numbers are frequencies obtained by two-dimensional model. 


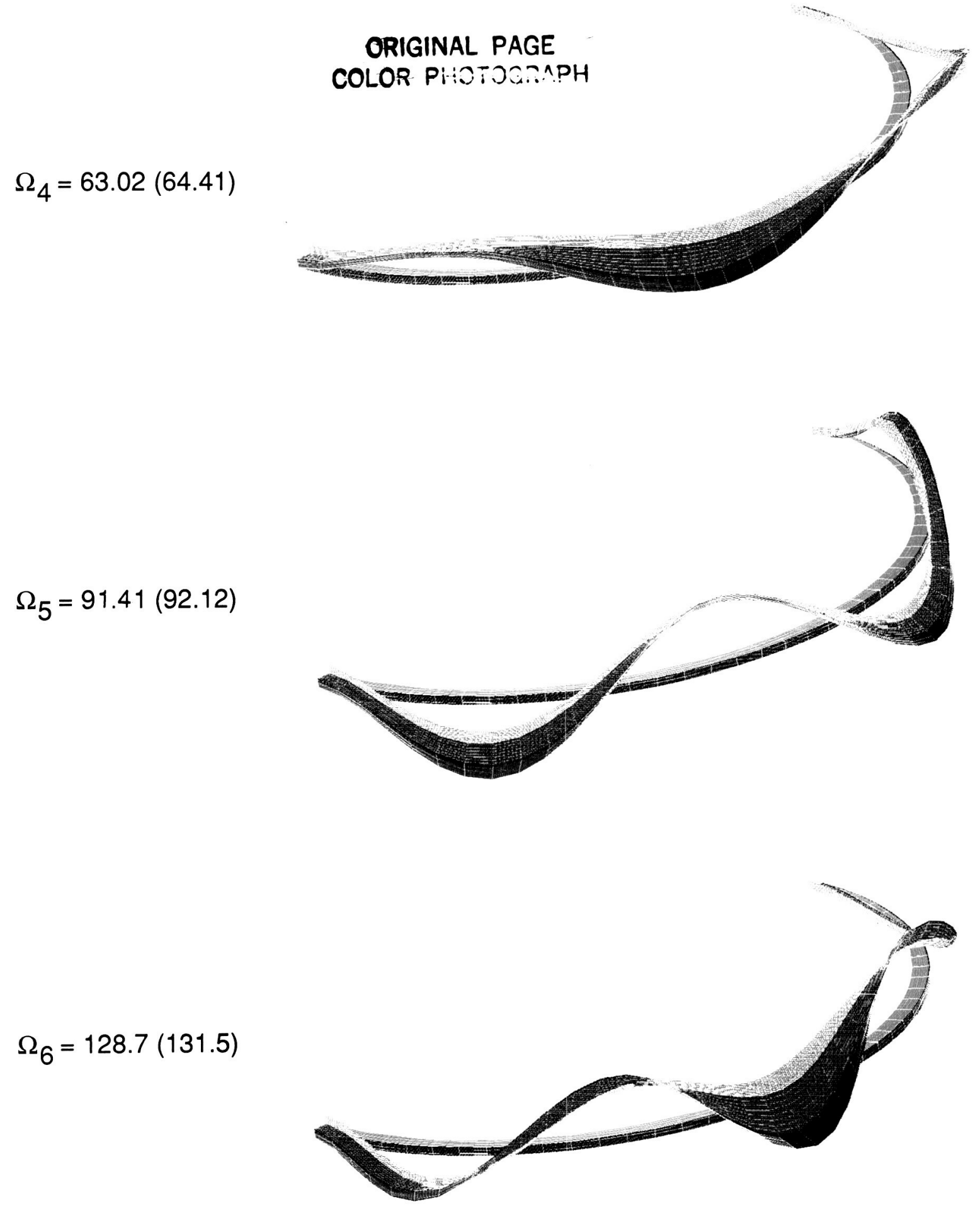

Figure 9. Concluded. 


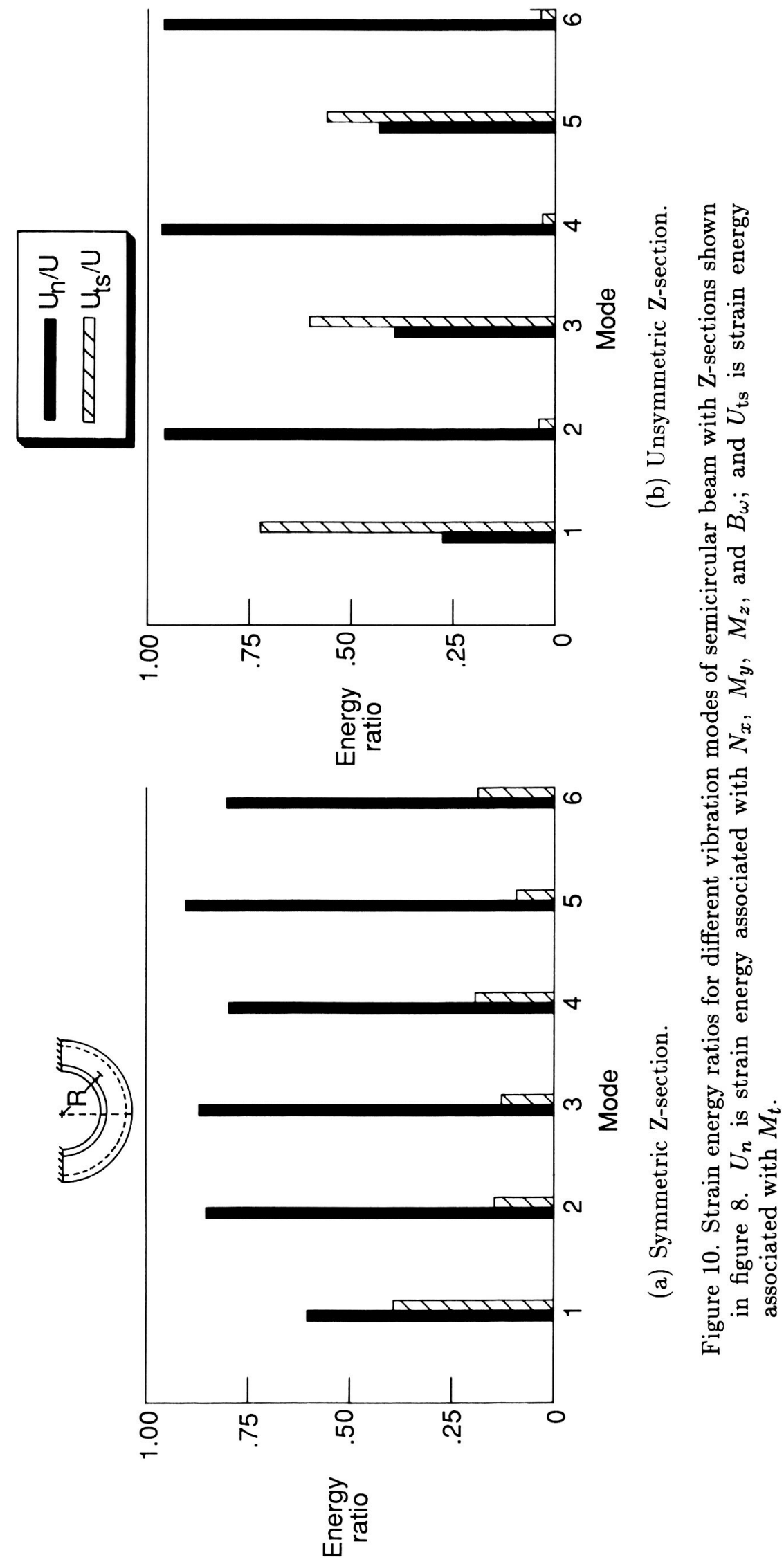




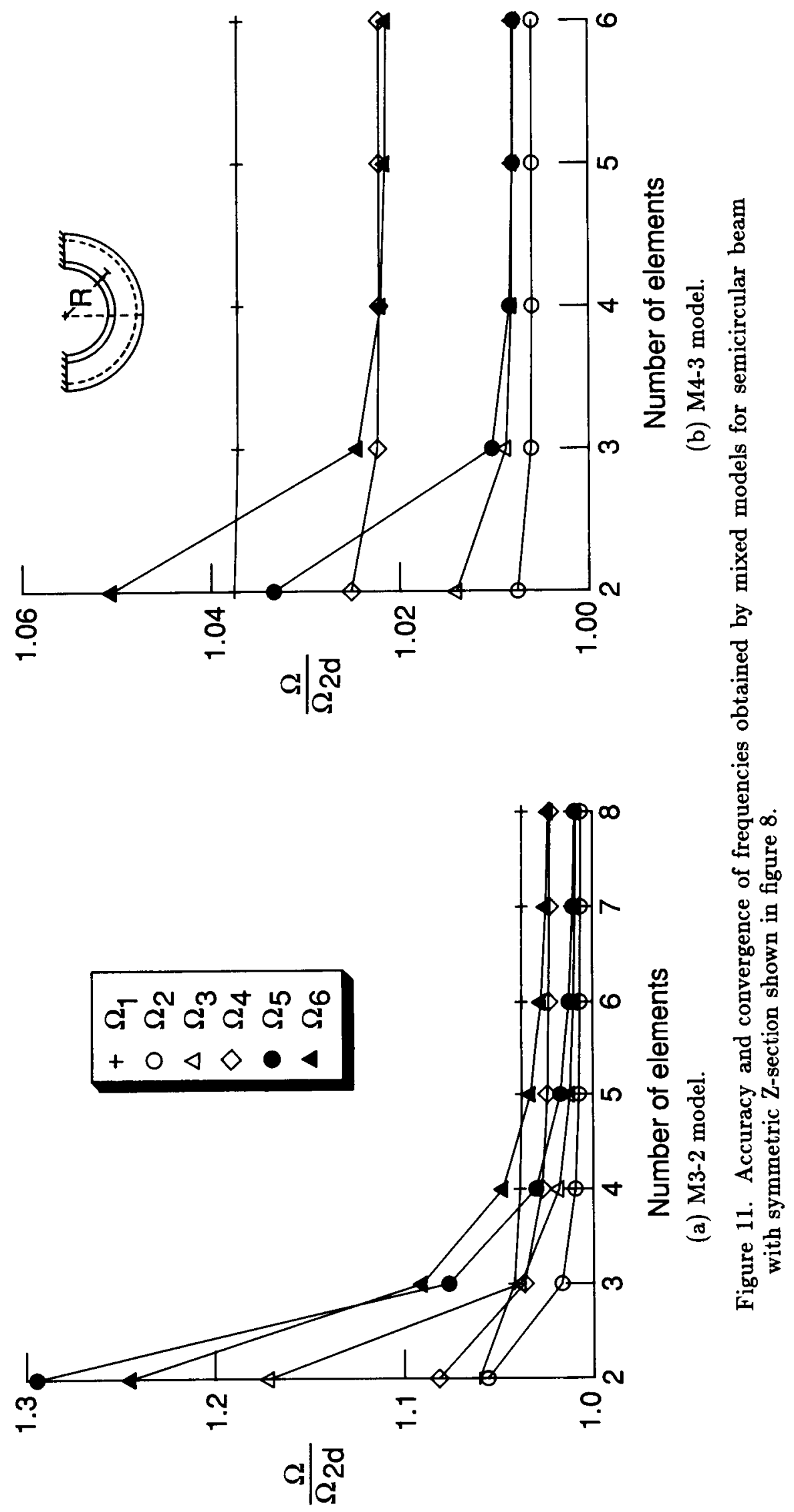




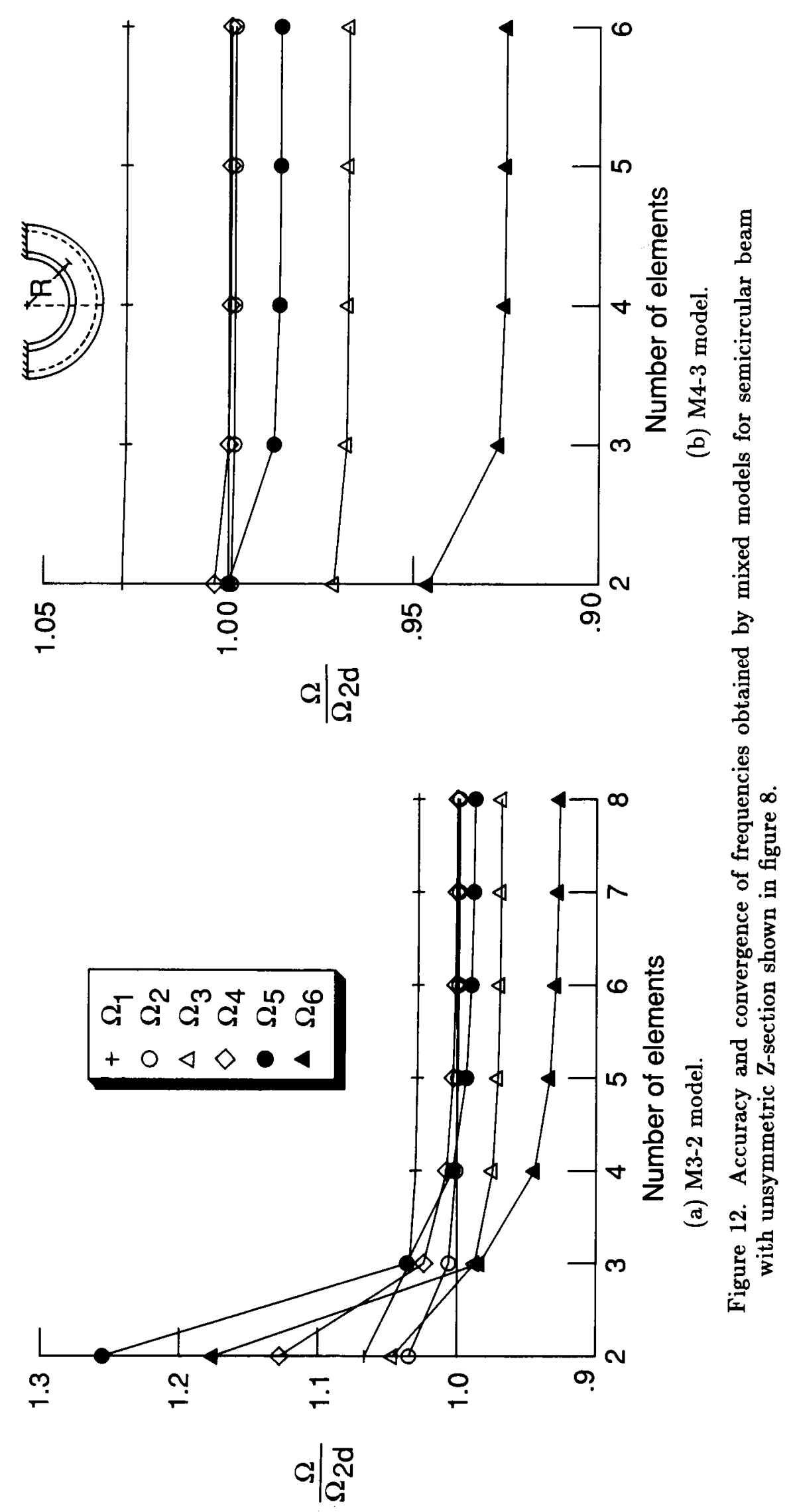




\begin{tabular}{|c|c|c|}
\hline \multicolumn{3}{|c|}{ Report Documentation Page } \\
\hline $\begin{array}{l}\text { 1. Report No. } \\
\text { NASA TP-2868 }\end{array}$ & 2. Government Accession No. & 3. Recipient's Catalog No. \\
\hline \multirow{2}{*}{\multicolumn{2}{|c|}{$\begin{array}{l}\text { 4. Title and Subtitle } \\
\text { Mixed Finite Element Models for Free Vibrations of Thin-Walled } \\
\text { Beams }\end{array}$}} & $\begin{array}{l}\text { 5. Report Date } \\
\text { February } 1989\end{array}$ \\
\hline & & 6. Performing Organization Code \\
\hline \multicolumn{2}{|c|}{$\begin{array}{l}\text { 7. Author(s) } \\
\text { Ahmed K. Noor, Jeanne M. Peters, and Byung-Jin Min }\end{array}$} & $\begin{array}{l}\text { 8. Performing Organization Report No. } \\
\text { L-16506 }\end{array}$ \\
\hline \multirow{2}{*}{\multicolumn{2}{|c|}{$\begin{array}{l}\text { 9. Performing Organization Name and Address } \\
\text { NASA Langley Research Center } \\
\text { Hampton, VA 23665-5225 }\end{array}$}} & \begin{tabular}{|c|} 
10. Work Unit No. \\
$505-63-41-02$
\end{tabular} \\
\hline & & 11. Contract or Grant No. \\
\hline \multirow{2}{*}{\multicolumn{2}{|c|}{$\begin{array}{l}\text { 12. Sponsoring Agency Name and Address } \\
\text { National Aeronautics and Space Administration } \\
\text { Washington, DC 20546-0001 }\end{array}$}} & $\begin{array}{l}\text { 13. Type of Report and Period Covered } \\
\text { Technical Paper }\end{array}$ \\
\hline & & 14. Sponsoring Agency Code \\
\hline \multicolumn{3}{|c|}{$\begin{array}{l}\text { 15. Supplementary Notes } \\
\text { Ahmed K. Noor, Jeanne M. Peters, and Byung-Jin Min: The George Washington University, } \\
\text { Joint Institute for Advancement of Flight Sciences, Langley Research Center, Hampton, Virginia. }\end{array}$} \\
\hline \multicolumn{3}{|c|}{$\begin{array}{l}\text { 16. Abstract } \\
\text { Simple, mixed finite element models are developed for the free-vibration analysis of curved, thin- } \\
\text { walled beams with arbitrary open cross section. The analytical formulation is based on a linear, } \\
\text { Vlasov-type, thin-walled beam theory with the effects of flexural-torsional coupling, transverse shear } \\
\text { deformation, and rotary inertia included. The fundamental unknowns consist of seven internal forces } \\
\text { and seven generalized displacements of the beam. The element characteristic arrays are obtained by } \\
\text { using a modified form of the Hellinger-Reissner mixed variational principle. Only } \mathrm{C}^{0} \text { continuity } \\
\text { is required for the generalized displacements. The internal forces and the Lagrange multiplier } \\
\text { are allowed to be discontinuous at interelement boundaries. Numerical results are presented to } \\
\text { demonstrate the high accuracy and effectiveness of the elements developed. The standard of } \\
\text { comparison is taken to be the solutions obtained by using two-dimensional plate/shell models for } \\
\text { the beams. }\end{array}$} \\
\hline
\end{tabular}

17. Key Words (Suggested by Authors(s))

Thin-walled beams

Perturbed Lagrangian formulation

Flexural-torsional coupling

Free vibrations

Mixed finite element models

18. Distribution Statement Unclassified-Unlimited

\begin{tabular}{|l|l|l|l|}
\hline $\begin{array}{l}\text { 19. Security Classif.(of this report) } \\
\text { Unclassified }\end{array}$ & $\begin{array}{l}\text { 20. Security Classif.(of this page) } \\
\text { Unclassified }\end{array}$ & $\begin{array}{c}\text { 21. No. of Pages } \\
27\end{array}$ & $\begin{array}{c}\text { 22. Price } \\
\text { A03 }\end{array}$ \\
\hline
\end{tabular}

